\title{
Untreated and Sargassum wightii-treated brilliant green dye toxicity impact on microflora and Allium cepa L.
}

\author{
D. Vigneshpriya ${ }^{1}{ }^{1} \cdot$ N. Krishnaveni ${ }^{1} \cdot$ S. Renganathan ${ }^{2}$
}

Received: 31 May 2018 / Accepted: 9 January 2019 / Published online: 14 January 2019

(c) The Author(s) 2019

\begin{abstract}
Seaweed Sargassum wightii is one of the most important marine resources as they have biological activity. Numerous researchers have reported on brilliant green dye decolourization using various seaweed. Despite its impact on after treatment, little information is available on the effect of seaweed-treated dye toxicity against plants and microorganisms. The present investigation was carried out to assess the microbial toxicity of $S$. wightii-treated and untreated dye using various microorganisms and cytotoxicity effect on Allium cepa $\mathrm{L}$. In this study, untreated dye which has substantial amount of the colour in it exhibited significant toxic effect against major gram-positive and gram-negative bacteria. The clear zone of inhibition exhibited by the untreated dye around bacterial and fungal colonies reflects its extent of microbial toxicity and infers that the untreated dye has antibacterial and antifungal activity. No inhibition zones were observed with treated dye when compared with the untreated dye. Consequently, treated dye does not exhibit microbial toxicity due to the complete absence of the dye in it. Cytotoxicity study on A. cepa grown in untreated dye solution showed decrease in root growth, increase in the mitotic index and chromosomal damage, whereas A. cepa bulbs grown in seaweed-treated dye showed betterment in root growth, increase in the mitotic index and decrease in chromosomal damage. Results of the cytotoxicity study indicated the untreated dye solution exerts toxic effect on A. cepa, whereas treated dye solution did not pose any toxic effect. This indirectly proves the efficiency of marine algae in complete removal of the dye from the present study. Thus, worldwide awareness of dye removal from aqueous solution and its management could be provoked.
\end{abstract}

Keywords Seaweed $\cdot$ Brilliant green dye $\cdot$ Microbial toxicity $\cdot$ Cytotoxicity

\section{Introduction}

Industrial effluents entering the water bodies are one of major sources of environmental toxicity. It plays an imperative role in degrading the water quality by releasing their effluents into soil and water bodies. These are not only toxic

D. Vigneshpriya

vipriya.aqua@gmail.com

N. Krishnaveni

venisekar1958@gmail.com

S. Renganathan

rengsah@rediffmail.com

1 Department of Zoology, Avinashilingam Institute for Home Science and Higher Education for Women, Coimbatore, Tamil Nadu 641 043, India

2 Department of Biotechnology, Alagappa College of Technology, Anna University, Chennai, Tamil Nadu 600 025, India to human welfare but also have deleterious impact on the microflora and plants. Water bodies and soil are the most favourable habitats for a wide range of microorganisms and plants. The contaminated water reduces the penetration of light, affects the photosynthesis of aquatic flora and makes the water aesthetically objectionable for drinking and other purposes.

The decolourization of the dye is a great challenge for the industries, since they are persistent in nature (Vigneshpriya and Shanthi 2016). These dyes are usually treated by physical or chemical treatment methods due to their faster treatment rate, but these are not economically feasible (Yao et al. 2010) and generate large amount of sludge and their byproducts are more toxic which requires further disposal (Fatima et al. 2015; Asgher and Bhatti 2012). Adsorption by activated carbon is also too expensive, thus novel economical, easily available and highly effective adsorbents are the need of the hour. 
Several studies on brilliant green (BG) dye decolourization using various bioadsorbent have been conducted, whereas no study was reported on and toxicological analysis after treatment. The main purpose of biodecolorization is detoxification, because dyes in wastewater are very recalcitrant and may be inhibitory to plants and microbial consortia of covenantal treatment. After the decolourization, toxicological analysis is needed for any treated industrial wastewater before discharged into water bodies, so that they can be used for monitoring and screening of surface water for functional capability of aquatic biotopes (Asgher et al. 2008). And also importantly to know whether biosorption (decolourization) of a dye has led to its detoxification or not.

Thus, based on the literature survey, we selected the BG dye and marine macro-alga Sargassum wightii which are popularly known as brown seaweed as biosorbent to decolourize dye. In this manner, our previous study (decolurization) results reported that $S$. wightii has an efficient to decolourize BG dye from aqueous solution (Vigneshpriya et al. 2017). Thus, the present study was concentrated on toxicological test of untreated and S. wightii-treated dye. Allium cepa L. has been widely used for the ecotoxicological testing and in situ risk evaluation of environmental contaminants including dyes, pesticides, food preservation and evaluation of environmental contaminants (Ashraf and Hussain 2010). Thus, the application plays an imperative role in biomonitaring since onion roots were sensitive for any toxic materials. Also to the best of our knowledge, numerous studies have been published on the antimicrobial activities of plant seaweed extracts against different types of microbes, including food and water borne pathogens. However, little information is available on the effect or potential of the antimicrobial role of brown $S$. wightii-treated dye. Thus, the aim of the present study was to evaluate the microbial toxicity of $S$. wightii-treated dye on pathogenic bacteria and fungi and cytotoxicity on A. серa $\mathrm{L}$.

\section{Materials and methods}

\section{Dye and chemicals}

Brilliant green dye was purchased from Sigma-Aldrich, Mumbai, India, of $90 \%$ purity and used without further purification. All other chemicals used in the present study were of analytical grade. Deionized water was used for all dilutions.

\section{Preparation of BG dye solution and decolourization of BG dye}

Dye solution was prepared by dissolving accurately weighed dye in distilled water at a concentration of $10 \mathrm{mg} / \mathrm{L}$ and left overnight to make the dye powder fully dissolved. The bottle was covered with aluminium foil in order to prevent the decolourization caused by light and stored in dark environment at room temperature. In next day, $0.1 \mathrm{~g}$ of adsorbent was added to decolourize BG dye from aqueous solution. Decolourization was monitored by UV-visible spectroscopic analysis. The spectrum was recorded using Schimadzu UV-1800 at a range of $200-800 \mathrm{~nm}$. The initial and final absorbance values of untreated and treated peaks of BG dye were used to determine the intensity of dye decolourization (Vigneshpriya et al. 2017). After decolourization study, untreated and $S$. wightii-treated BG dye solution was taken for toxicological evaluation.

\section{Microbial toxicity assay of untreated and $S$. wightii-treated dye}

\section{Bacterial toxicity}

The bacterial toxicity of untreated and treated dye was determined by agar-well diffusion method. Mueller-Hinton agar (MH) (Himedia, Mumbai, India) plates were swabbed (sterile cotton swabs) with 0.1 OD cultures of gram-positive (three cultures) and gram-negative (seven cultures) bacteria. Using the sterile cork borer, wells $(6 \mathrm{~mm})$ were made into each petriplate. $10 \mu \mathrm{l}$ of untreated dye and treated dye were introduced into separate wells and distilled water served as control. Then, the plates were incubated at $37^{\circ} \mathrm{C}$ for $24 \mathrm{~h}$ (Kahraman and Yalcin 2005). After the incubation period, the diameter of the inhibition zones of each well was measured and the values were tabulated.

\section{Fungal toxicity}

The fungal toxicity of untreated and treated dye was determined by agar-well diffusion method. Potato dextrose agar (PDA) (Himedia, Mumbai, India) plates were swabbed (sterile cotton swabs) with 0.1 OD fungal cultures. Using the sterile cork borer, wells $(6 \mathrm{~mm})$ were made into each petriplate. $10 \mu \mathrm{l}$ of untreated dye and treated dye were introduced into separate wells and distilled water served as control. Then, the plates were incubated at room temperature for 48-72 h (Rani et al. 2014). After the incubation period, the diameter of the inhibition zones of each well was measured and the values were tabulated.

\section{Cytotoxicity study of untreated and S. wightii-treated dye}

\section{Selection of $A$. cepa for toxicity assay}

Allium cepa is a widely used experimental plant in cytotoxicity studies because it has a suitable chromosome and 
good correlation with mammalian test system. In order to test the cytotoxic effect of BG dye, the onion bulbs were exposed to control (T1), untreated (T2) and treated (T3) BG dye solution.

\section{Collection and preparation of onion bulbs}

Commercially available onion (Allium cepa L.) bulbs were used for cytotoxicity studies using the standard protocol (Fiskesjo 1985). The purple variety of equal sized (width: 20-25 mm, weight: 6-12 mg) onion bulbs (Allium cepa. L) were obtained from local market of Coimbatore, Tamil Nadu, India. The bulbs were air-dried for 10 days, and the outer dry, brown scales were removed. The dried roots were carefully removed with a sharp razor blade and placed in distilled water to protect the primordial cells from drying up.

The equal sized bulbs were exposed to control, untreated and treated dye solution, and each group consisted three replicates. For each treatment group, treatment solutions and control were changed for every $24 \mathrm{~h}$ till $72 \mathrm{~h}$. After $72-\mathrm{h}$ exposure, the roots of the bulbs were removed with a forceps and their lengths were measured in centimetre with a metre scale. After sufficient root growth $(1-2 \mathrm{~cm})$, the bulbs were removed and washed in distilled water.

After washing, the root tips were cut and fixed in absolute alcohol and glaciel acetic acid (3:1) for $12 \mathrm{~h}$ (Haq et al. 2016). After that, the root meristems were cut and stained with $0.5 \%$ acetocarmine for $5 \mathrm{~min}$ without hydrolysis. Stained root tips were squashed on microscopic slides and covered with cover slips to visualize the scrabble stages under microscope.

\section{Scoring}

The slides were viewed under the binocular light microscope using the $100 \times$ objective lens with oil immersion. A total of 1000 cells were scored per slide and the most representative abnormalities were photographed. Mitotic index and mitotic depression were calculated following the procedure of Das (1986) and Kar (1992)

Mitotic Index $(\mathrm{MI})=\frac{\text { No. of dividing cells }}{\text { Total no. of cells scored }} \times 100$

Mitotic Depression $(\mathrm{MD})=\frac{\mathrm{MI}(\text { control })-\mathrm{MI}(\text { treated })}{\mathrm{MI}(\text { control })} \times 100$

\section{Statistical analyses}

Toxicity results obtained were subjected to one-way analysis of variance (ANOVA), and mean separation was accomplished by Duncan's multiple range test (DMRT) for significant differences $(P \leq 0.05)$ using STATISTICA software (1999).

\section{Results and discussion}

\section{Bacterial toxicity of the untreated and treated BG dye}

The untreated and treated dye solution (Fig. 1) was tested for their bacterial toxicity against gram-positive as well as gram-negative bacteria (Table 1). Untreated dye which has substantial amount of the dye exhibited significant bacterial toxicity. It exhibited vibrant and clear inhibition zone of diameter of about $2.1 \mathrm{~cm}$ against Escherichia coli, followed by Salmonella sp. (2 cm). Marginally high zone of inhibition $(1.8 \mathrm{~cm})$ was observed against Streptococcus epidermis, Staphylococcus aureus and Shigella sp. Next to it, the untreated dye exhibited considerable zone of inhibition $(1.7 \mathrm{~cm})$ against Pseudomonas aeruginosa and Proteus vulgaris. Moderate inhibition zones of diameter $1.5 \mathrm{~cm}, 1.4 \mathrm{~cm}$ and $1.2 \mathrm{~cm}$ were observed against Bacillus cereus, Vibrio cholera and Klebsiella sp., respectively (Fig. 2). The clear zone of inhibition exhibited by the untreated dye reflected its extent of microbial toxicity and inferred that the untreated dye had antibacterial activity. The index of toxicity was represented by the zone size. No inhibition zones were observed with $S$. wightii-treated dye which also confirmed the nontoxic nature of the extracted metabolite.

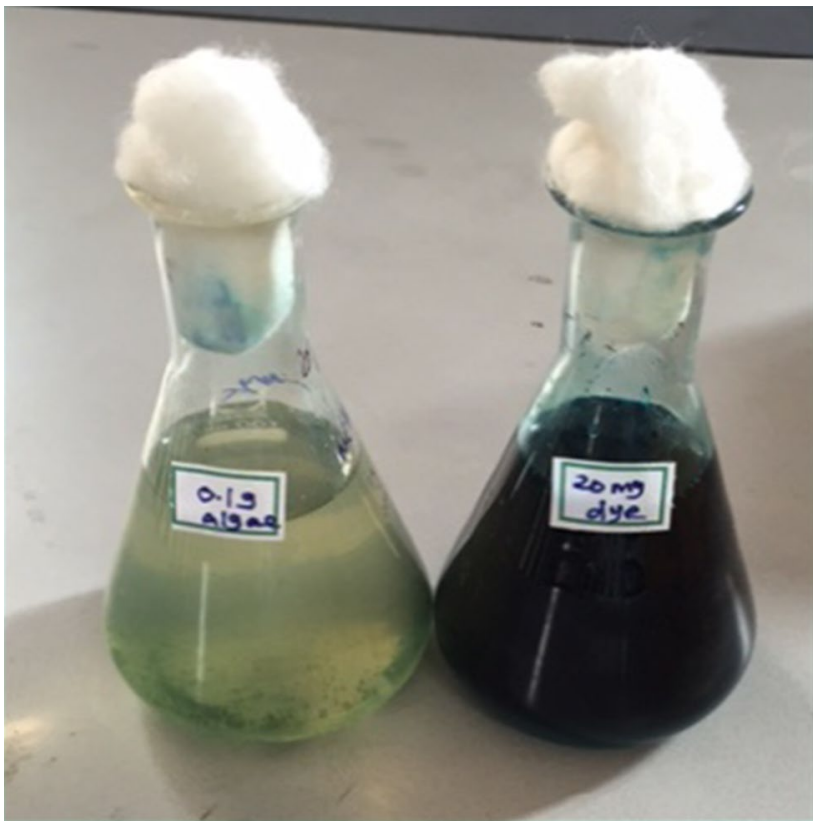

Fig. 1 Sargassum wightii-treated and untreated BG dye

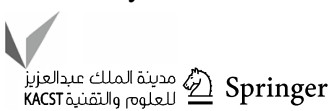


Table 1 Bacterial toxicity of the untreated and treated dye

\begin{tabular}{|c|c|c|c|c|}
\hline \multirow[t]{2}{*}{ S. no. } & \multirow[t]{2}{*}{ Organisms } & \multicolumn{3}{|c|}{$\begin{array}{l}\text { Diameter of the zone of inhibition } \\
(\mathrm{cm})\end{array}$} \\
\hline & & Control & Untreated BG dye & $\begin{array}{l}\text { Treated } \\
\text { BG dye }\end{array}$ \\
\hline 1. & Klebsiella sp. & NI & $1.2 \pm 0.29$ & NI \\
\hline 2. & $\begin{array}{l}\text { Streptococcus epi- } \\
\quad \text { dermis }\end{array}$ & NI & $1.8 \pm 0.15$ & NI \\
\hline 3. & Vibrio cholera & NI & $1.4 \pm 0.16$ & NI \\
\hline 4. & $\begin{array}{l}\text { Pseudomonas aerugi- } \\
\quad \text { nosa }\end{array}$ & $\mathrm{NI}$ & $1.7 \pm 0.14$ & $\mathrm{NI}$ \\
\hline 5. & Shigella sp. & NI & $1.8 \pm 0.15$ & NI \\
\hline 6. & Bacillus cereus & NI & $1.5 \pm 0.24$ & NI \\
\hline 7. & Proteus vulgaris & NI & $1.7 \pm 0.14$ & NI \\
\hline 8. & Salmonella enteriditis & NI & $2.0 \pm 0.13$ & NI \\
\hline 9. & Staphylococcus aureus & NI & $1.8 \pm 0.15$ & NI \\
\hline 10. & Escherichia coli & NI & $2.1 \pm 0.12$ & NI \\
\hline
\end{tabular}

NI No zone of inhibition

(Results are the mean value of triplicates \pm standard deviation with significant difference at $P<0.05$ )

Potent bacterial toxicity of the untreated dye might be due to the presence of BG dye (one of the triarylmethane dyes), which is used as an effective antiseptic agent. Similar inhibitory results were obtained by Bakker et al. (1992) who experimented the activity of brilliant green against Streptococcus, Proteus and Staphylococcus sp. Parshetti et al. 2011 suggested the degradation products were less toxic compared with crystal violet to an exploited microorganism such as $A$. radiobacter, a phosphate-solubilizing bacterium $P$. aeruginosa and nitrogen-fixing bacterium $A$. vinelandii.

Kahraman and Yalcin (2005) studied the antimicrobial effect of the treated dyes on $P$. aeruginosa which was tested to evaluate the toxicity after decolourization. The untreated dyes used were toxic, and their effects increased with the concentration gradually. It was found that the treated dyes were less toxic and also the removal of treated Astrazone black and Astrazone yellow with cotton stalk reduced the toxic effect on P. aeruginosa. According to Brahmbhatt and Jasrai (2016), untreated and treated effluents were tested for their effect on the agriculturally important soil bacterial flora, Azotobacter sp. and Rhizobium sp. From their experiment, no zone of inhibition was obtained for decolorized dye water which indicated that the biodegraded or decolorized product was nontoxic to beneficial soil bacteria. The results were also in agreement with Mali et al. (2000) who studied the toxic effect of biodegraded products on agriculturally important soil microflora like Bacillus sp. (phosphate solubulizer), Rhizobium and Azotobacter (nitrogen fixers). They reported from the zone of inhibition that it is nontoxic to soil beneficial microflora which is necessary for sustainable agricultural practices.
Microbial toxicity of the textile azo dye (Reactive Red 81) was studied on microorganisms Azotobacter sp., Pseudomonas sp. and Rhizobium sp, and their results showed that the wells with decolorized broth showed no zone of inhibition but wells with original dye exhibited a zone of inhibition. This confirmed that the original dye solution $(3000 \mu \mathrm{g} / \mathrm{ml})$ was toxic to the bacteria but its degradation products were nontoxic according to Shertate and Thorat (2016). Also microbial bioassay of basic fuchsin showed that untreated dye inhibited the growth of $E$. coli (forming a zone of inhibition) when compared to the treated (no zone of inhibition) (Rani et al. 2014).

\section{Fungal toxicity of the untreated and treated BG dye}

The untreated and treated dye solution was also tested for their fungal toxicity against few prominent fungal cultures, Rhizopus sp., Aspergillus flavus, Acremonium sp., Trichoderma viride, Aspergillus fumigatus and Aspergillus niger (Table 2). Eminent zones of inhibition were observed in the untreated dye when compared with the treated dye (no zone of inhibition). Largest zone of inhibition $(0.8 \mathrm{~cm})$ was observed against Rhizopus sp., Trichoderma viride, Aspergillus fumigatus and Aspergillus niger. Considerable inhibition zone of diameter $0.6 \mathrm{~cm}$ was observed against Aspergillus flavus and Acremonium sp. (Fig 3). Treated dye did not exhibit antifungal activity.

BG dye has been used widely as an antifungal agent in fish hatcheries (Allen et al. 1994; Culp and Beland 1996; Srivastava et al. 2004). Similar results were obtained by lyas and Rehman (2013), reported no zone of inhibition when using Aspergillus niger and Nigrospora sp. The results of this study (Rani et al. 2014) suggested that potentially competent fungal strains can be efficiently used for detoxification and bioremediation of harmful dyes. Thus, detoxification ability of seaweed is directly proved against bacterial and fungal growth bioassay. Absence of zone of inhibition, in the case of treated dye, infers complete removal of the dye by the marine algae (S. wightii). Hence, treated dye does not exhibit microbial toxicity due to the complete absence of the dye in it. This indirectly proves the efficiency of marine alga $S$. wightii in complete removal of the dye from the present study.

\section{Cytotoxicity of the treated and untreated BG dye}

In this study, treated and untreated BG dye solution was analysed for their toxicity potential by the $A$. серa $\mathrm{L}$. The macroscopic results clearly showed that toxicity of the dye prompted A. cepa root growth inhibition. After 72-h exposure, maximum root length was observed in onion bulbs grown in treated dye solution (T3) and control (T1). The 
Fig. 2 Toxicity (bacterial) of the untreated and treated dye samples against 1. Klebsiella sp. 2. Streptococcus epidermi 3. Vibrio cholera 4. Pseudomonas aeruginosa 5. Shigella sp. 6. Bacillus cereus 7. Proteus vulgaris 8. Salmonella sp. 9. Staphylococcus aureus and 10. Escherichia coli

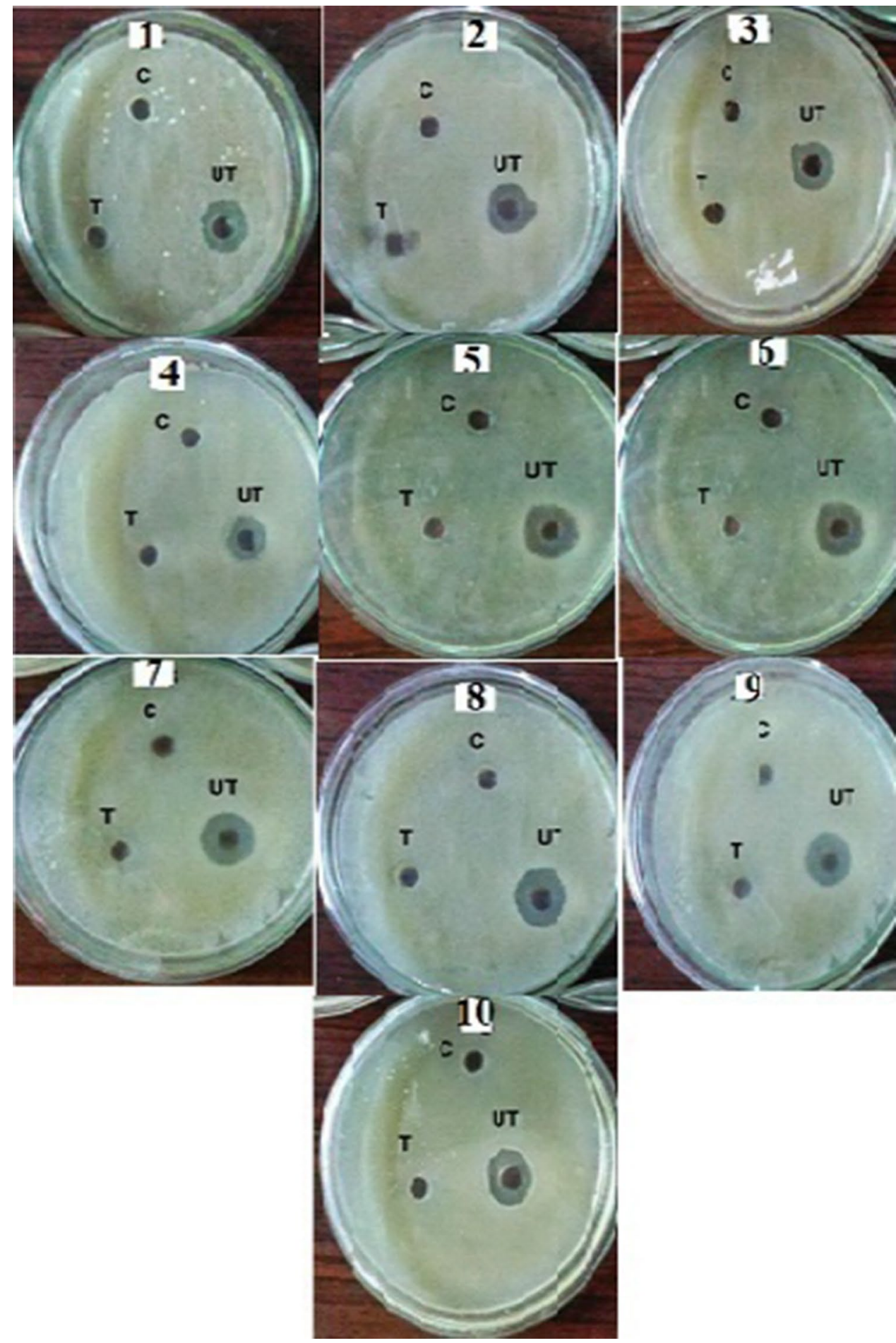

minimum root length was observed in bulbs grown in untreated dye solution (T2) (Table 3).

Table 4 describes the impact of control, untreated and $S$. wightii-treated BG dye on number of dividing cells, mitotic indices (MI) and mitotic depression (MD). A total of 1000 cells were scored for control and each treatment. The maximum number of dividing cells was observed in control $(735.2 \pm 3.9)$ and $S$. wightii-treated BG dye $(659.4 \pm 2.1)$ exposed bulbs. The minimum number of dividing cells was observed in onion bulbs grown in untreated BG dye $(161.7 \pm 0.2)$. To study the MI (mitotic index), 1000 cells were counted for each treatment group. From Table 4, MI of samples exposed to $S$. wightii-treated dye $(68.9 \pm 2.1)$ was significantly higher $(P<0.05)$ and 
Table 2 Fungal toxicity of the untreated and treated dye

\begin{tabular}{lllll}
\hline S. no. & Organisms & \multicolumn{2}{l}{$\begin{array}{l}\text { Diameter of the zone of inhibition } \\
\text { (in cm) }\end{array}$} \\
\cline { 3 - 5 } & & Control & Untreated BG dye & $\begin{array}{l}\text { Treated } \\
\text { BG dye }\end{array}$ \\
\hline 1. & Rhizopus sp. & NI & $0.8 \pm 0.53$ & NI \\
2. & Aspergillus flavus & NI & $0.6 \pm 0.38$ & NI \\
3. & Acremonium sp. & NI & $0.6 \pm 0.38$ & NI \\
4. & Trichoderma viride & NI & $0.8 \pm 0.53$ & NI \\
5. & Aspergillus fumigates & NI & $0.8 \pm 0.53$ & NI \\
6. & Aspergillus niger & NI & $0.8 \pm 0.53$ & NI \\
\hline
\end{tabular}

NI No zone of inhibition \pm

(Results are the mean value of triplicates \pm standard deviation with significant difference at $P<0.05$ )

close to that of control $(73.5 \pm 3.9)$ might be due to the potential of $S$. wightii in the removal of pollutants. Significant reduction $(P<0.05)$ was observed in untreated dye sample $(16.1 \pm 0.2)$. The mitotic depressionthat observed significantly minimum number $(P<0.05)$ in treated BG dye $(12.9 \pm 7.2)$ was close to that of control $(12.5 \pm 5.3)$. In contrast, maximum number of mitotic depression was observed in untreated BG dye $(98.2 \pm 6.4)$. Besides, treated dye that showed less number of alterations compared to the untreated dye includes the abnormal cells and occurrence of different chromosomal aberrations like bridge formation, laagering of chromosome, binuclear cells, polyploidy cells and multinucleated cell etc. (Table 5). A similar result was observed by Phugare et al. (2010) and was observed that cells exposed to treated dye showed minimum alterations because of the depletion of pollution loads after treatment.

The similar observation was reported by Tripathy and Patel (2014) who stated that the high concentration of dye reduces the mitotic index and increases the rate of mitotic abnormalities. Stickiness is the indicator and also signifies high toxicity of dye which will lead to irreversibility of chromosomal aberrations and cell death (Alimba et al. 2013). This result similar to the previous report, in which onion bulbs were exposed to pulp and paper mill effluent, induced chromosomal aberrations and nuclear abnormalities compared to the control bulbs (Haq et al. 2016).
Fig. 3 Toxicity (fungal) of untreated and treated dye samples against 1. Rhizopus sp. 2. Aspergillus flavus 3. Acremonium sp 4. Trichoderma viride 5. Aspergillus fumigates and 6 . Aspergillus niger
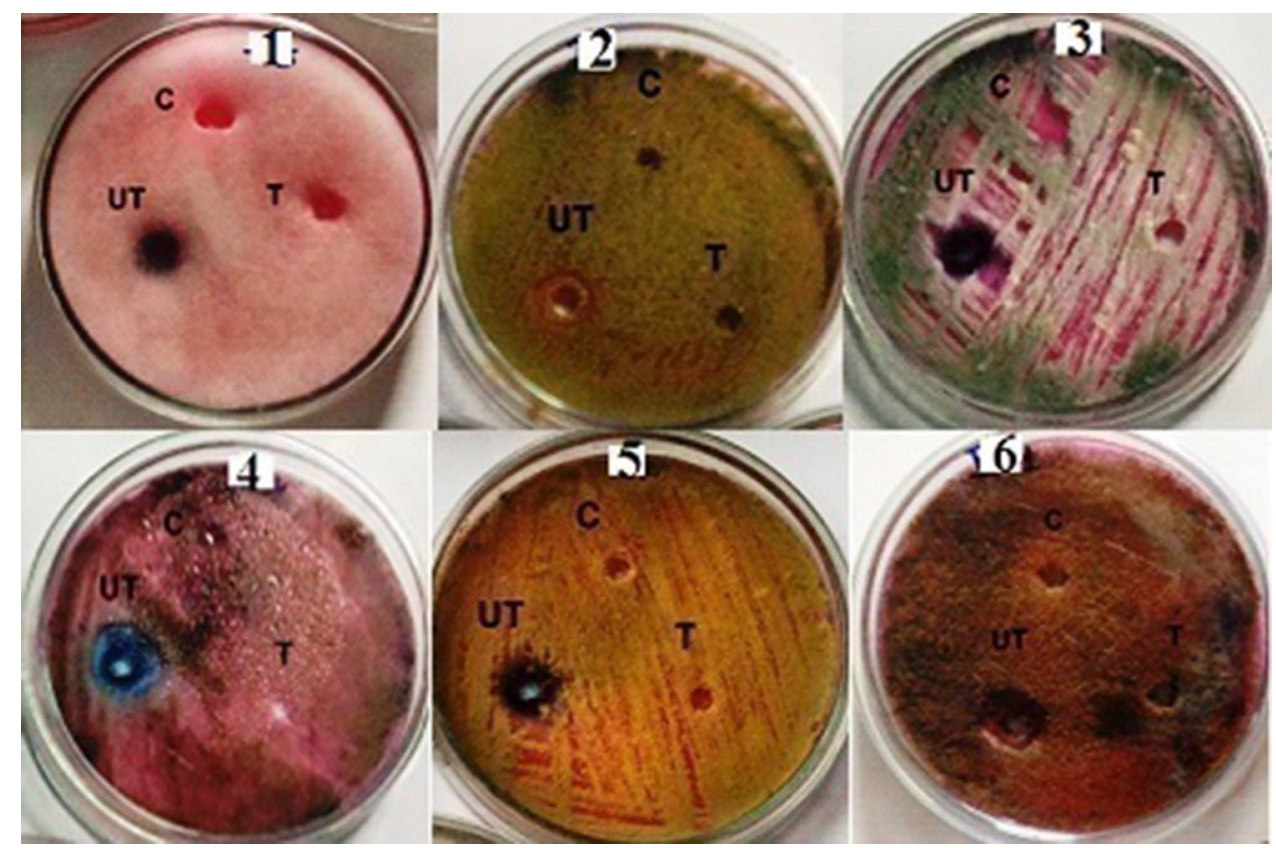

Table 3 Root length of Allium cepa grown in control, untreated and S. wightii-treated BG dye solution

\begin{tabular}{|c|c|c|c|c|c|c|c|c|c|}
\hline \multirow{2}{*}{$\begin{array}{l}\text { Duration } \\
\text { (in h) }\end{array}$} & \multicolumn{3}{|l|}{ Control } & \multicolumn{3}{|c|}{ Untreated BG dye } & \multicolumn{3}{|c|}{ Treated BG dye } \\
\hline & T1 (a) & $\mathrm{T} 1$ (b) & $\mathrm{T} 1$ (c) & $\mathrm{T} 2$ (a) & $\mathrm{T} 2$ (b) & $\mathrm{T} 2(\mathrm{c})$ & $\mathrm{T} 3$ (a) & T3 (b) & $\mathrm{T} 3$ (c) \\
\hline 24 & $1.13 \pm 0.50$ & $1.31 \pm 0.40$ & $1.35 \pm 0.36$ & $0.67 \pm 0.27$ & $0.42 \pm 0.30$ & $0.45 \pm 0.20$ & $1.26 \pm 0.17$ & $1.36 \pm 0.30$ & $1.42 \pm 0.19$ \\
\hline 48 & $1.23 \pm 0.28$ & $1.43 \pm 0.26$ & $1.41 \pm 0.32$ & $0.35 \pm 0.13$ & $0.35 \pm 0.23$ & $0.43 \pm 0.26$ & $1.30 \pm 0.30$ & $1.33 \pm 0.27$ & $1.45 \pm 0.18$ \\
\hline 72 & $1.29 \pm 0.22$ & $1.35 \pm 0.44$ & $1.45 \pm 0.17$ & $0.80 \pm 0.52$ & $0.58 \pm 0.31$ & $0.47 \pm 0.19$ & $1.37 \pm 0.26$ & $1.37 \pm 0.21$ & $1.40 \pm 0.26$ \\
\hline
\end{tabular}

(Results are the mean value \pm standard deviation with significant difference at $P<0.05$ ) 
Table 4 Mitotic index and mitotic depression of Allium cepa (onion bulbs) grown in control, untreated and S. wightii-treated BG dye solution

\begin{tabular}{llll}
\hline Treatments & Cells in division & Mitotic index & Mitotic depression \\
\hline Control & $735.2 \pm 3.9$ & $73.5 \pm 3.9$ & $12.5 \pm 5.3$ \\
Untreated & $161.7 \pm 0.2$ & $16.1 \pm 0.2$ & $98.2 \pm 6.4$ \\
Treated & $659.4 \pm 2.1$ & $68.9 \pm 2.1$ & $12.9 \pm 7.2$ \\
\hline
\end{tabular}

Represents mean \pm standard deviation with significant difference at $P<0.05)$

Table 5 Effect of untreated and S. wightii-treated BG dye on the induction of chromosomal aberration in Allium cepa

\begin{tabular}{lllc}
\hline Chromosome aberrations & Control & $\begin{array}{l}\text { Untreated } \\
\text { BG dye }\end{array}$ & $\begin{array}{c}\text { Treated } \\
\text { BG dye }\end{array}$ \\
\hline Chromosomes with spindle distur- & - & 14 & 2 \\
$\quad$ bances & & & \\
Anaphase chromosome bridge & 1 & 9 & 20 \\
Normal telophase & 45 & 3 & 52 \\
Disturbed metaphase & - & 27 & 3 \\
Laggard chromosome & - & 11 & 5 \\
Chromosome displacement at ana- & - & 25 & - \\
$\quad$ phase & & & \\
Normal prophase & 50 & 40 & 64 \\
Sticky chained metaphase & - & 33 & 14 \\
Chromosome bridge at telophase & - & 97 & 5 \\
Chromosome fragment & - & 78 & 8 \\
Normal metaphase & 35 & 30 & 49 \\
Normal spindle fibre separation & - & 46 & 18 \\
Disturbed prophase & - & 92 & 5 \\
Chromosome bridge at late anaphase & - & 32 & 3 \\
Sticky chromosomes & - & 46 & 6 \\
Normal anaphase & 36 & 25 & 35 \\
Abnormal grouping of chromosomes & - & 87 & 2 \\
Equatorial separation at anaphase & - & 63 & 2 \\
Abnormal telophase & - & 89 & 3 \\
Chromosomes in equatorial plate & 27 & 64 & 5 \\
Telophase with chromosomal loss & - & 93 & 2 \\
\hline & & & \\
\hline
\end{tabular}

This confirmed the interference of the chemicals presence in the dye, whereas the bulbs grown in treated dye solution did not show any inhibition effect on root elongation. Also the roots grew well due to the elevation dye. Untreated dye solution is believed to be toxic as they might exist various harmful effects after treatment dye revealed the nontoxic nature. It also showed that the dye induced chromosomal aberrations at significant levels. The results revealed that the untreated dye was toxic to eukaryotic cells.

\section{Conclusions}

Bioremediation integrates the intensity of pollution and environmental effects, forming a major research outcome. By responding to the bioavailable concentration of a pollutant, they measure its impact on the environment more accurately. This is vital in assessing environmental clean-up. $S$. wightii-treated dye could have integrated with decolourization and revealed that it does not lead to detoxification of the dye, whereas untreated dye reflected its extent of microbial toxicity and toxic to eukaryotic cells. Cytotoxicity study indicated the untreated dye solution exerts toxic effect on A. cepa whereas treated dye solution did not pose any toxic effect. The decolourization of dye using marine macro-alga is cost-effective and promising alternative to replace the physical and chemical treatment techniques. Hence, this study concluded the reduction in toxic effect of $S$. wightiitreated dye decreasing the environment damage.

Acknowledgements The authors thank the Department of Zoology, Avinashilingam Institute for Home Science and Higher Education for Women, Coimbatore, Tamil Nadu, India, for providing laboratory facilities. We are also thankful to the Department of Microbial Biotechnology, Bharathiar University, Coimbatore, Tamil Nadu, India, for providing the necessary facilities.

Open Access This article is distributed under the terms of the Creative Commons Attribution 4.0 International License (http://creativeco mmons.org/licenses/by/4.0/), which permits unrestricted use, distribution, and reproduction in any medium, provided you give appropriate credit to the original author(s) and the source, provide a link to the Creative Commons license, and indicate if changes were made.

\section{References}

Alimba CG, Ogunkanmi AL, Ogunmmola FJ (2013) Cytotoxic and genotoxic assessment of textile effluent using Allium assay. Curr Top Toxicol 9:65-74

Allen JL, Gofus JE, Meinertz JR (1994) Determination of malachite green residues in the eggs, fry and adult muscle tissue of rainbow trout (Oncorhynchus mykiss). JAOAC Int 77:553-557

Asgher M, Bhatti HN (2012) Evaluation of thermodynamics and effect of chemical treatments on sorption potential of citrus waste biomass for removal of anionic dyes from aqueous solutions. Ecol Eng 38:79-85

Asgher M, Bhatti HN, Ashraf M, Legge RL (2008) Recent developments in biodegradation of industrial pollutants by white rot fungi and their enzyme system. Biodegradation 19:771-783

Ashraf H, Hussain Q (2010) Studies on bitter gourd peroxidase catalyzed removal of P- bromophenol from wastewater. Desalination 262(1-3):267-272

Bakker P, Van Doorne H, Gooskens V, Wieringa NF (1992) Activity of gentian violet and brilliant green against some microorganisms associated with skin infections. Int J Dermatol 31:210-213

Brahmbhatt NH, Jasrai RT (2016) Bidegradation of reactive dyes by two microalgal species. Int J Sci Res 4(5):1697-1702

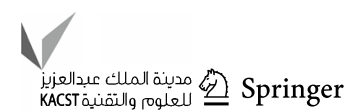


Culp SJ, Beland FA (1996) Malachite green a toxicological review. J Am Coll Toxicol 15:219-238

Das RK (1986) In vivo cytogenetic assays for evaluating genotoxicity of pharmaceuticals. Perspective in Cytology and Genetics (eds Manna GK, Sinha U) 5:13-19

Fatima N, Omm-e-Hany Al, Alamgir A (2015) Decolourization of textile effluent through indigenous microorganism. Bull Environ Pharmacol Life Sci 4(5):109-115

Fiskesjo G (1985) The allium test as standard in environmental monitoring. Hereditas 102:99-112

Haq I, Kumari V, Kumar S, Raj A, Lohani M, Bhargava RN (2016) Evaluation of the phytotoxic and genotoxic potential of pulp and paper mill effluent using Vigna radiata and Allium cepa. Adv Biol 2016:1-10

Kahraman S, Yalcin P (2005) Antibacterial effect of untreated and treated (Decolourized) dyes by agricultural wastes. Am J Biochem Biotechnol 1(1):50-53

Kar NR (1992) Effects of textile mill effluent on root tips of onion (Allium cepa). A thesis submitted to Sambalpur University, Odisha, India for the partial fulfilment of the award of the degree on Master of Philosophy in Life Sci, pp 06-07

lyas S, Rehman A (2013) Decolourization and detoxification lolf synozol red HF- 6BN azo dye, by Aspergillus niger and Niogrospora sp. Iran J Environ Health Sci Eng 10:12

Mali PL, Maharajan MM, Patil DP, Kulkarni MV (2000) Biodecolourization of members of Triphenyl methane and azo group of dyes. J Sci Ind Res 59(3):221-224

Parshetti GK, Parshetti SG, Telke AA, Kalyani DC, Doonq RA, Govindwar SP (2011) Biodegradation of crystal violet by Agrobacterium radiobacter. J. Environ Sci 23(18):1384-1393

Phugare S, Patil P, Govindwar S, Jadhav J (2010) Exploitation of yeast biomass generated as a waste product of distillery industry for remediation of textile industry effluent. Int Biodeterior Biodegrad 64(716):726

Rani B, Kumar V, Singh J, Bisht S, Teotia P, Sharma S, Kela R (2014) Bioremediation of dyes by fungi isolated from contaminated dye effluent sites for bio-usability. Braz J Microbiol 45(3):1055-1063

Shertate RS, Thorat PR (2016) Bioremedial potential of marine bacterium. World J Pharm Res 5(5):1130-1150

Srivastava S, Sinha R, Roy D (2004) Toxicological effects of malachite green. Aquat Toxicol 66:319-329

STATSOFT, INC (1999) Statistica for Windows [Computer program manual]. Tulsa, OK: StatSoft, Inc., 2300 East 14th Street, Tulsa, OK 74104

Tripathy SK, Patel S (2014) Abnormal mitosis in root meristem cells of Allium cepa $\mathrm{L}$ induced by a fabric dye reactive turquoise blue (Procion MX). Afr J Biotechnol 13(38):3881-3891

Vigneshpriya D, Shanthi E (2016) Biosorption of textile effluent using sugarcane bagasse. Int J Curr Res 8(2016):31324-31331

Vigneshpriya D, Krishnaveni N, Renganathan S (2017) Marine brown macroalga Sargassum wightii as novel biosorbent for the removal of brilliant green dye from aqueous solution: Kinetics, equilibrium isotherm modeling and phytotoxicity of treated and untreated dye. Desalination Water Treat 78(2017):300-312

Yao Y, Xu F, Chen M, Xu Z, Zhu Z (2010) Adsorption behavior of methylene blue on carbon tubules. Bioresour Technol 101:3040

Publisher's Note Springer Nature remains neutral with regard to jurisdictional claims in published maps and institutional affiliations. 